\title{
Ultrasound Role in Diagnosis of Carpal Tunnel Syndrome and Postoperative Evaluation in Endoscopic Carpal Tunnel Release
}

\author{
Hossam Elsobky¹, Mohamed Kassem¹, Tamer Youssif², Ahmed Abd-Elkhalek ${ }^{3}$, Amr Farid Khalil ${ }^{1}$ \\ ${ }^{1}$ Neurosurgery Department, Mansoura University, Mansoura, Egypt \\ ${ }^{2}$ General Surgery Department, Mansoura University, Mansoura, Egypt \\ ${ }^{3}$ Diagnostic and Interventional Radiology Department, Mansoura University, Mansoura, Egypt \\ Email: dr_amr77@yahoo.com
}

How to cite this paper: Elsobky, H., Kassem, M., Youssif, T., Abd-Elkhalek, A. and Khalil, A.F. (2019) Ultrasound Role in Diagnosis of Carpal Tunnel Syndrome and Postoperative Evaluation in Endoscopic Carpal Tunnel Release. Open Journal of Modern Neurosurgery, 9, 248-257.

https://doi.org/10.4236/ojmn.2019.93024

Received: May 12, 2019

Accepted: May 26, 2019

Published: May 29, 2019

Copyright $\odot 2019$ by author(s) and Scientific Research Publishing Inc. This work is licensed under the Creative Commons Attribution International License (CC BY 4.0).

http://creativecommons.org/licenses/by/4.0/

\begin{abstract}
Carpal tunnel syndrome (CTS) represents about $90 \%$ of all entrapment neuropathies and is caused by entrapment of the median nerve while passing in the carpal tunnel. US has revealed equal effectiveness as magnetic resonance imaging (MRI) in diagnosis of CTS; however further attention should be given in case of equivocal results from nerve conduction studies (NCS) and/or before endoscopic surgical intervention. This study was conducted to evaluate the role of US in diagnosis and treatment of CTS which was done by endoscopic release. This is a prospective study including patients having CTS who were treated by endoscopic release between December 2017 and December 2018. All cases were evaluated by electrophysiological studies and US at the preoperative period. US was used to measure the cross sectional area (CSA) of the median nerve. Patients underwent endoscopic carpal tunnel release and were called for follow up after 1, 3, and 6 months for clinical and US assessment of the median nerve. Forty cases were included with mean age of 27.85 years. Numbness was the predominant symptom (92.5\%) followed by wrist pain $(85 \%)$. The mean diameter of median nerve showed a significant decrease at different time points $(\mathrm{P}<0.001)$. The sensitivity of US in diagnosis of CTS was $87.5 \%$ in the preoperative assessment as compared to electrophysiological study. The sensitivity of US in detecting the improvement of CTS as compared to clinical examination increased from $28 \%$ at 1 month postoperative, $53.4 \%$ at 3 months to $92.1 \%$ at 6 months. Ultrasonography is a sensitive non-invasive diagnostic tool in diagnosis of CTS preoperative and diagnosis of improvement of the patients postoperatively especially at 6 months.
\end{abstract}

\section{Keywords}

Carpel Tunnel Syndrome, Ultrasonography, Endoscopic Release 


\section{Introduction}

Carpal tunnel syndrome (CTS) is the commonest one of upper limb compression neuropathies. It represents about $90 \%$ of all entrapment neuropathies. CTS is caused by entrapment of the median nerve while passing in the carpal tunnel at the level of the wrist [1].

CTS is widely distributed in as an occupational health condition; especially in workers who are exposed to activities that include high force/pressure or the use of repetitive vibrating appliances. CTS has an unclear, multifactorial etiology: often one only etiology cannot be recognized. A variety of causative factors can affect the median nerve in the carpal tunnel [2].

The diagnosis of CTS remains to be neurophysiologically and clinically debated. Certain clinical examinations have been used as components of a clinical diagnosis of CTS; however, their accuracy has been a matter of debate. The traditional symptoms of CTS include pain, numbness, and tingling in the areas supplied by the median nerve, but numbness may be extended to affect all the fingers. Symptoms usually worsen at night and can arouse subjects from sleep. In order to decrease the intensity of symptoms, patients usually "flick" their wrist as if shaking down a thermometer (flick sign). In cases with CTS, pain and parathesia may be extended to include forearm, elbow, and shoulder. In cases of severe CTS, there is usually loss of dexterity and atrophy of thenar muscle that finally lead to weak hand grip [3].

Although there are many clinical tests for diagnosis of CTS; however none of these tests is diagnostic on its own, but they complete each other to confirm the final diagnosis. These tests are Tinel's sign, Phalen's sign, square wrist sign, closed fist sign, flick sign, Katz hand diagram, flexion and extension of wrist test, pressure provocation test, and tourniquet test. Recently, imaging modalities like Ultrasonography and MRI have been found to be worth in the diagnosis of CTS [4].

It has been reported that US has equal effectiveness as magnetic resonance imaging (MRI); however further attention should be given in case of equivocal results from nerve conduction studies (NCS) and/or before endoscopic surgical intervention [5].

Despite of different etiologies that may cause CTS, the US features of CTS include three diagnostic features: 1) swelling of the median nerve at the entry of the carpal tunnel (the cross-sectional area $>10 \mathrm{~mm}^{2}$ ), 2) flattening of the median nerve in the distal carpal tunnel with a ratio of 3 and 3) amplified palmar bowing of the flexor retinaculum [6].

Advantages to US in CTS include the following: 1) it is readily obtainable, 2) a non-invasive maneuver, 3) has a short time in examination and 4) can be used to evaluate many parameters of the median nerve such as size, vascularity and mobility. Also, US carries the advantage of providing sufficient data about the anatomical variation of the median nerve and its surroundings [7].

Surgical therapy of CTS involves dissecting the transverse ligament of the palm, with subsequent release of the pressure on the median nerve. Endoscopic 
carpal tunnel release (ECTR) is a relatively novel technique, first being introduced in 1989 by Chow and Okutsu. It needs use of special instruments, such as an endoscopic camera, optic fiber light source and a screen for monitoring [8].

There are few numbers of literatures that were published about the effectiveness of US as a sensitive noninvasive tool for diagnosis of CTS preoperative and follow up the patients in the postoperative period. Our study was done to evaluate the role of ultrasonography in diagnosis and treatment of Carpal Tunnel Syndrome which is done by endoscopic release.

\section{Patients and Methods}

This is a Prospective observational study conducted at neurosurgical department, Mansoura University Hospitals, between December 2017 and December 2018 Egypt. 40 patients were included in this study with the following inclusion criteria: 1) Age of patients between 20 - 60 years old, 2) Symptoms and signs of CTS, 3) EMG revealed a decrease of the sensory conduction velocity of the median nerve and 4) Prolongation of the distal motor latency and Patient completed understanding of the procedure plus written consent signature. The exclusion criteria in our study involved patients with previous surgery of the wrist, anatomical variation of the median nerve, proximal median neuropathy, polyneuropathy or cervical radiculopathy and recurrent cases.

All cases were subjected to complete history taking, through Clinical and full Laboratory investigations. Moreover, Radiological investigation that was ordered included: electrophysiologic studies and ultrasound. The songraphic diagnostic criteria of carpal tunnel syndrome potentially included distal flattening of the nerve, palmar bowing of the flexor retinaculum, and enlargement of the nerve proximal to the flexor retinaculum.

The CSA of the median nerve was measured by US with a Xario ${ }^{\circ}$ Toshiba apparatus and a linear $12 \mathrm{MHz}$ multifrequency transducer over the distal palmar surface of the wrist (at the level of the proximal flexion fold). At the beginning of the procedure, the pisiform bone knobs and the scaphoid tubercle are palpated and the process of measurement was conducted by a single sonographer who was blind for the patients' clinical data. The patients were seated, with the arm in supination on a table, with the wrist in neutral position and the semiflexed fingers at rest. The CSA was automatically calculated by the US apparatus on the basis of a continuous line drawn by the sonographer around the nerve margin defined as the external margin of the hypoechoic nerve fascicles and the interior of the hyperechoic nerve sheath. A CSA $\geq 9 \mathrm{~mm}$ was considered to be diagnostic for CTS [9].

All cases underwent endoscopic carpel tunnel release under supraclavicular blockade as shown in Figure 1 and Figure 2.

Patients were discharged on the middle of $1^{\text {st }}$ POD commenced on oral analgesics and nerve tonics. Stitches were removed at the OPC after 10 days. Follow up clinical examination and ultrasonographic examinations were done at $1^{\text {st }}, 3^{\text {rd }}$, and $6^{\text {th }}$ months postoperatively as shown in Figure 3 . 


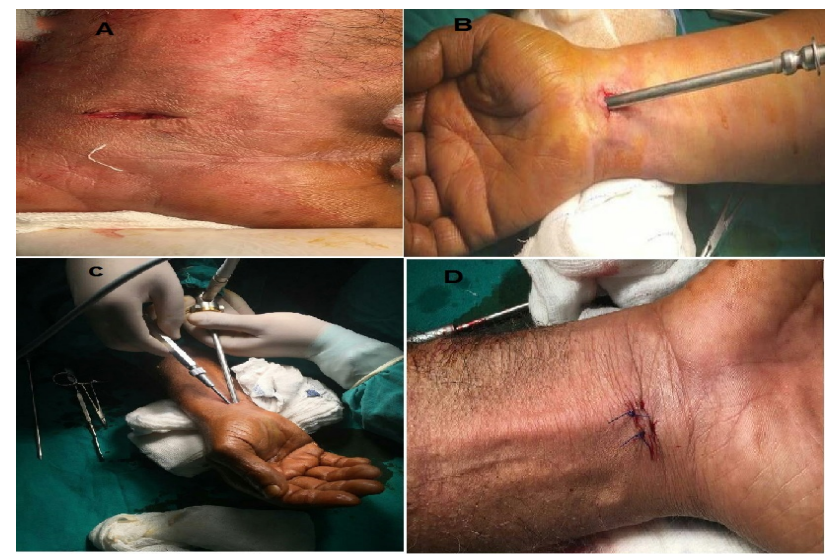

Figure 1. Steps of operation of endoscopic release of flexor retinaculum.

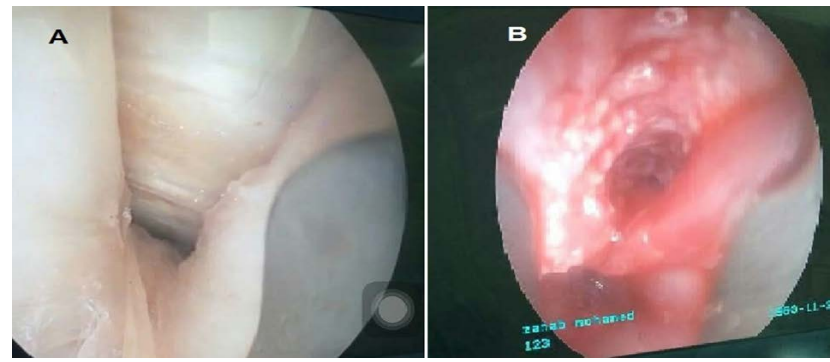

Figure 2. Flexor retinaculum and median nerve. A: before release of flexor retinaculum. B: after release of the retinaculum.

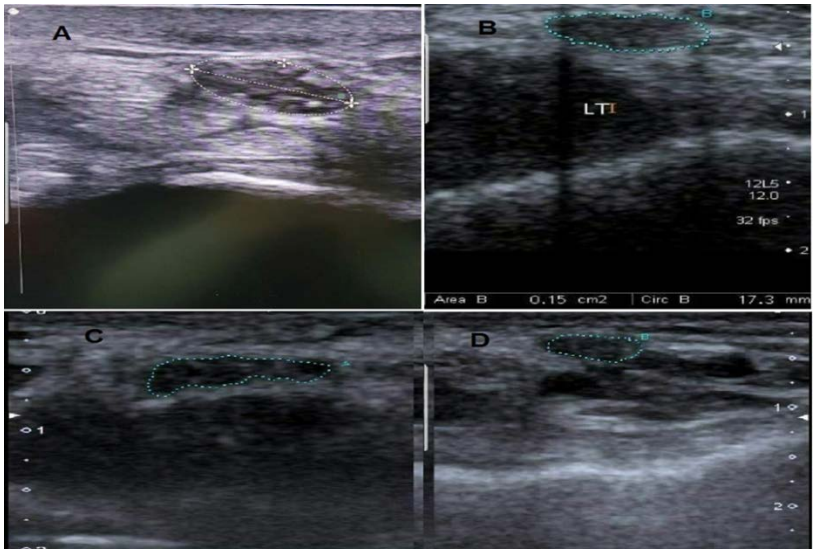

Figure 3. US examination of median nerve diameter (the dotted area). A: preoperative, B: at 1 month, C: at 3 months, D: at 6 months.

\section{Statistical Analysis}

Data was analyzed by using SPSS software, version 20 (Chicago, IL). Quantitative data were expressed as means with standard deviation or medians with ranges according to data distribution. One way ANOVA was used to compare quantitative data at different time points. Validity of US were expressed in terms of sensitivity, specificity, NPV and PPV. P values $<0.05$ are considered significant. 


\section{Results}

As illustrated in Table 1, the mean age was 27.85 years with SD of 5.25. The mean BMI was 23.67 years with SD of 2.13. As regards the gender distribution, 14 cases (35\%) were males and 26 cases $(65 \%)$ were females. Regarding the presence of associated chronic diseases 4 cases (10\%) are diabetic.

The mean duration from suffering from symptoms related to carpel tunnel syndrome affection was 11.18 months with SD of 2.31 . The most reported symptoms among cases were numbness that was present in 37 (92.5\%) of cases. Pain was the second most common symptom and was present in 34 (85\%) of cases. These data are illustrated in Table 2.

By using ANOVA test, a significant $(\mathrm{P}<0.001)$ change was found in the mean diameter of median nerve at different time points. Regarding the analysis of the individual difference between two time points, there was a significant difference in the median nerve diameter at 1, 3 and 6 months postoperatively as compared to the preoperative diameter.

As shown in Table 3, there was also a significant difference in the median nerve diameter at 3 and 6 months postoperatively as compared to its diameter at 1 month postoperative. The mean diameter of median nerve revealed no statistically significant difference in its value at 3 and 6 months postoperatively.

Assessment of $\mathrm{U} / \mathrm{S}$ in diagnosis of carpel tunnel syndrome as compared to electrophysiological studies, our study revealed that the sensitivity of US was $87.5 \%$ in the preoperative assessment. These data are illustrated in Table 4.

Assessment of U/S in diagnosis of improvement of carpel tunnel syndrome as compared to clinical examination at 1 month postoperative, our study revealed that Sensitivity was $28 \%$, specificity was $86.7 \%$, PPV was $77.8 \%$, and NPV was 41.9\%. These data are illustrated in Table 5.

Assessment of U/S in diagnosis of improvement of carpel tunnel syndrome as compared to clinical examination at 3 months postoperative, our study revealed that Sensitivity was $53.4 \%$, specificity was $33.3 \%$, PPV was $78.2 \%$, and NPV was $11.1 \%$. The data are shown in Table 6.

As shown in Table 7, the assessment of U/S in diagnosis of improvement of carpel tunnel syndrome as compared to clinical examination at 6 months postoperative, our study revealed that Sensitivity was $92.1 \%$, specificity was $100 \%$, PPV was $100 \%$, and NPV was $40 \%$.

Table 1. Demographic data of the cases within the study.

\begin{tabular}{ccc}
\hline Age & $27.85 \pm 5.25$ \\
\hline BMI & $23.67 \pm 2.13$ \\
\hline Males & Gender & \\
Females & 14 & $35 \%$ \\
\hline $\begin{array}{c}\text { Chronic diseases } \\
\text { (Diabetes mellitus) }\end{array}$ & 26 & $65 \%$ \\
\hline
\end{tabular}


Table 2. Analysis of symptoms the cases within the study.

\begin{tabular}{cc}
\hline Numbness & $37(92.5 \%)$ \\
\hline Pain & $34(85 \%)$ \\
Duration of symptoms (Months) & $11.18 \pm 2.31$ \\
\hline
\end{tabular}

Table 3. Comparison of the median nerve diameter as measured by U/S.

\begin{tabular}{cccccc}
\hline \multirow{2}{*}{$\begin{array}{c}\text { median } \\
\text { nerve } \\
\text { diameter }\end{array}$} & Pre-operative & $\begin{array}{c}\text { Post-operative } \\
\text { (1 month) }\end{array}$ & $\begin{array}{c}\text { Post-operative } \\
\text { (3 months) }\end{array}$ & $\begin{array}{c}\text { Post-operative } \\
\text { (6 month) }\end{array}$ & $\begin{array}{c}\text { ANOVA test } \\
\text { P-value }\end{array}$ \\
\cline { 2 - 4 } & & $12.93 \pm 1.29$ & $11.05 \pm 1.18$ & $9.51 \pm 1.46$ & \\
\hline Mean $\pm \mathrm{SD}$ & $14.22 \pm 2.36$ & $0.001^{*}$ & $<0.001^{*}$ & $<0.001^{*}$ & $\mathrm{~F}=30.886$ \\
$\mathrm{P}_{1}$ & & & $<0.001^{*}$ & $<0.001^{*}$ & $\mathrm{P}<0.001^{*}$ \\
$\mathrm{P}_{2}$ & & & & 0.083 & \\
$\mathrm{P}_{3}$ & & & & 0.083 & \\
\hline
\end{tabular}

*: Statistically significant $(\mathrm{p} \leq 0.05)$, F: one way ANOVA.

Table 4. Assessment of U/S in diagnosis of carpel tunnel syndrome as compared to electrophysiological study.

\begin{tabular}{|c|c|c|c|}
\hline \multirow{4}{*}{$\mathrm{U} / \mathrm{S}$} & \multirow{2}{*}{ Interpretation } & \multicolumn{2}{|c|}{ EMG study } \\
\hline & & Affected $(\mathrm{N}=40)$ & Free $(\mathrm{N}=0)$ \\
\hline & Affected $(\mathrm{N}=35)$ & 35 & 0 \\
\hline & Free $(\mathrm{N}=5)$ & 5 & 0 \\
\hline Sensitivity & & $87.5 \%$ & \\
\hline
\end{tabular}

Table 5. Assessment of Validity of U/S in diagnosis of carpel tunnel syndrome as compared to clinical examination (1 month).

\begin{tabular}{|c|c|c|c|}
\hline \multirow{4}{*}{$\mathrm{U} / \mathrm{S}$} & \multirow{2}{*}{ Interpretation } & \multicolumn{2}{|c|}{ Clinical examination } \\
\hline & & Improved $(\mathrm{N}=25)$ & Not improved $(\mathrm{N}=15)$ \\
\hline & Improved $(\mathrm{N}=9)$ & 7 & 2 \\
\hline & Not improved $(\mathrm{N}=31)$ & 18 & 13 \\
\hline Sensitivity & & $28 \%$ & \\
\hline Specificity & & $86.7 \%$ & \\
\hline PPV & & $77.8 \%$ & \\
\hline NPV & & $41.9 \%$ & \\
\hline
\end{tabular}

Table 6. Assessment of U/S in diagnosis of carpel tunnel syndrome as compared to clinical examination (3 months).

\begin{tabular}{cccc}
\hline \multirow{2}{*}{ U/S } & Interpretation & \multicolumn{2}{c}{ Clinical examination } \\
\cline { 2 - 4 } & Improved $(\mathrm{N}=22)$ & 18 & Not improved $(\mathrm{N}=6)$ \\
\cline { 2 - 4 } & Not improved $(\mathrm{N}=18)$ & 16 & 2 \\
\hline Sensitivity & $53.4 \%$ & \\
Specificity & $33.3 \%$ & \\
PPV & $78.2 \%$ & \\
NPV & $11.1 \%$ & \\
\hline
\end{tabular}


Table 7. Assessment of U/S in diagnosis of carpel tunnel syndrome as compared to clinical examination (6 months).

\begin{tabular}{cccc}
\hline & \multirow{2}{*}{ Interpretation } & \multicolumn{2}{c}{ Clinical examination } \\
\cline { 2 - 4 } U/S & & Improved $(\mathrm{N}=38)$ & Not improved $(\mathrm{N}=2)$ \\
\cline { 2 - 4 } & Improved $(\mathrm{N}=35)$ & 35 & 0 \\
\cline { 2 - 4 } & Not improved $(\mathrm{N}=5)$ & $92.1 \%$ & 2 \\
\hline Sensitivity & $100 \%$ & \\
Specificity & $100 \%$ & \\
PPV & $40 \%$ & \\
NPV &
\end{tabular}

\section{Discussion}

Carpal tunnel syndrome is the most common peripheral compressive neuropathy, responsible for more than $90 \%$ of all compressive neuropathies. motor, sensory, and autonomic nerves impairment (either alone or in combination) are the responsible causes of the clinical manifestations of CTS such as intrinsic hand weakness, weak hand grip, pain, numbness, and thermal control change of the wrist and hand [10].

Both history of symptoms and physical examination used to diagnose CTS and electrodiagnostic studies are often used for confirmation. electrodiagnostic studies have revealed $85 \%$ sensitivity and $95 \%$ specificity for diagnosing CTS, but they are invasive and can't be tolerated by many patients [11].

Ultrasonography (US) is now well established as a diagnostic tool in CTS because it carries many advantages such as it is readily available, non-invasive, characterized by shorter time of examination and can be used to assess a number of parameters of the median nerve such as size, vascularity (using power Doppler) and mobility (using dynamic imaging). Also, US carries the advantage of providing sufficient data about the anatomical variation of the median nerve and its surroundings [12].

This number of patients in our study is considered relatively low as compared with other studies like El Miedany and his colleagues who included 233 patients with carpel tunnel syndrome in their study [5]. Also another study performed in the year 2015 that included 200 patients with carpel tunnel syndrome [13]. Within the same context, another study included 264 symptomatic hands with carpel tunnel syndrome [14].

Regarding the results of our study, there was a significant difference in the median nerve diameter at 1,3 and 6 months postoperatively as compared to the preoperative diameter. There was also a significant difference in the median nerve diameter at 3 and 6 months postoperatively as compared to its diameter at 1 month postoperative. There was no significant difference between the mean diameter of median nerve at 3 and 6 months postoperative.

Our study revealed that the sensitivity of US was $87.5 \%$ in the preoperative as 
compared to clinical and electrophysiological studies. Our study revealed that Sensitivity was $28 \%$, specificity was $86.7 \%$, PPV was $77.8 \%$, and NPV was $41.9 \%$ as compared to clinical evaluation at 1 month. These values have changed as follow at 6 months; Sensitivity was $92.1 \%$, specificity was $100 \%$, PPV was $100 \%$, NPV was $40 \%$.

In a study performed by El Miedany and his colleagues, the assessment of severity of symptoms of CTS and the median nerve diameter were conducted at baseline, 1-week, 1-month and 6-months post treatment. Moderate inverse correlation was found between the neural vasculature and the severity of CTS detected by NCS $(r=-0.648)$. In cases treated with conservative measures, improvement of US measures was detected within 1-week, while in surgically managed cases, there was an initial increase in the nerve measurement post-operatively, before it decreased again at 1-month time of follow-up. Increase in the vasculature of the median nerve (as detected by US) was also a good prognostic sign for early determination of median nerve affection [5].

Results of another study showed the significant increase in the measures of the cross sectional area (CSA), flattening ratio (FR) and the palmar bowing (PB) in the carpel tunnel syndrome patients, compared with the control group $(p<$ 0.05). The validity of ultrasonographic measurements in diagnosis of CTS was performed by using receiver operator characteristic (ROC) curve. The area under the curve (AUC) of CSA was 0.95 , with cut off value of $10.0 \mathrm{~mm}^{2}$ which revealed sensitivity and specificity of $88.5 \%$ and $90.0 \%$ respectively [14].

In another study, diagnostic values detected from different sonographic were compared to determine the optimal value of median nerve swelling, with area under the curves ranging from 0.75 to 0.85 . The largest CAS of the median nerve at 9.8 and $13.8 \mathrm{~mm}^{2}$ were associated with high sensitivity and specificity $(92 \%$ for both). The cutoff point of the power Doppler score for diagnosis of CTS was $\geq 2$ with $90 \%$ specificity. Sonographic median nerve volumetry revealed a good reliability with an interclass correlation coefficient of 0.90 (95\% CI 0.79 to 0.95 ) [15].

Also in another study, the sensitivity and specificity of a large CSA in the median nerve for the diagnosis of CTS were $71 \%$ and $91 \%$, respectively. In addition, we found a significant relationship between the number of pixels and the parameters obtained at gray-scale US [16].

The present study has some limitations, as it was a single-center study, and the sample size may be considered relatively small, which restricts the power of conclusions. Therefore, wide further improvements are needed in our future study.

\section{Conclusion}

Our results have revealed the diagnostic value of US in diagnosis carpel tunnel preoperative and detected the improvement after surgery. We recommend performing the US at six months after surgery due to higher rates of sensitivity and specificity. 


\section{Conflicts of Interest}

The authors declare no conflicts of interest regarding the publication of this paper.

\section{References}

[1] Trillos, M.C., Soto, F. and Briceno-Ayala, L. (2018) Upper Limb Neurodynamic Test 1 in Patients with Clinical Diagnosis of Carpal Tunnel Syndrome: A Diagnostic Accuracy Study. Journal of Hand Therapy, 31, 333-338. https://doi.org/10.1016/j.jht.2017.05.004

[2] Basiri, K. and Katirji, B. (2015) Practical Approach to Electrodiagnosis of the Carpal Tunnel Syndrome: A Review. Advanced Biomedical Research, 4, 50. https://doi.org/10.4103/2277-9175.151552

[3] Hultman, C.S. (2014) The Carpal-Tunnel Syndrome. Seventeen Years' Experience in Diagnosis and Treatment of Six Hundred Fifty-Four Hands, in 50 Studies Every Plastic Surgeon Should Know. CRC Press, Boca Raton, 59-65.

[4] Padua, L., Coraci, D., Erra, C., Pazzaglia, C., Paolasso, I., Loreti, C., et al. (2016) Carpal Tunnel Syndrome: Clinical Features, Diagnosis, and Management. The Lancet Neurology, 15, 1273-1284. https://doi.org/10.1016/S1474-4422(16)30231-9

[5] El Miedany, Y., El Gaafary, M., Youssef, S., Ahmed, I. and Nasr, A. (2015) Ultrasound Assessment of the Median Nerve: A Biomarker That Can Help in Setting a Treat to Target Approach Tailored for Carpal Tunnel Syndrome Patients. SpringerPlus, 4, 13. https://doi.org/10.1186/s40064-014-0779-4

[6] Keberle, M., Jenett, M., Kenn, W., Reiners, K., Peter, M., Haerten, R. and Hahn, D. (2000) Technical Advances in Ultrasound and MR Imaging of Carpal Tunnel Syndrome. European Radiology, 10, 1043-1050. https://doi.org/10.1007/s003300000386

[7] Roll, S.C., Case-Smith, J. and Evans, K.D. (2011) Diagnostic Accuracy of Ultrasonography vs. Electromyography in Carpal Tunnel Syndrome: A Systematic Review of Literature. Ultrasound in Medicine and Biology, 37, 1539-1553. https://doi.org/10.1016/j.ultrasmedbio.2011.06.011

[8] Chow, J.C.Y. and Hantes, M.E. (2002) Endoscopic Carpal Tunnel Release: Thirteen Years' Experience with the Chow Technique. Journal of Hand Surgery, 27, 1011-1018. https://doi.org/10.1053/jhsu.2002.35884

[9] Billakota, S. and Hobson-Webb, L.D. (2017) Standard Median Nerve Ultrasound in Carpal Tunnel Syndrome: A Retrospective Review of 1,021 Cases. Clinical Neurophysiology Practice, 2, 188-191. https://doi.org/10.1016/j.cnp.2017.07.004

[10] Ibrahim, I., Khan, W.S., Goddard, N. and Smitham, P. (2012) Carpal Tunnel Syndrome: A Review of the Recent Literature. The Open Orthopaedics Journal, 6, 69-76. https://doi.org/10.2174/1874325001206010069

[11] McDonagh, C., Alexander, M. and Kane, D. (2015) The Role of Ultrasound in the Diagnosis and Management of Carpal Tunnel Syndrome: A New Paradigm. Rheumatology (Oxford), 54, 9-19. https://doi.org/10.1093/rheumatology/keu275

[12] Kantarci, F., Ustabasioglu, F.E., Delil, S., Olgun, D.C., Korkmazer, B., Dikici, A.S., Mihmanli, I., et al. (2014) Median Nerve Stiffness Measurement by Shear Wave Elastography: A Potential Sonographic Method in the Diagnosis of Carpal Tunnel Syndrome. European Radiology, 24, 434-440. https://doi.org/10.1007/s00330-013-3023-7

[13] Castro, A., Skare, T.L., Nassif, P.A., Sakuma, A.K. and Barros, W.H. (2015) Sonographic Diagnosis of Carpal Tunnel Syndrome: A Study in 200 Hospital Workers. 
Radiologia Brasileira, 48, 287-291. https://doi.org/10.1590/0100-3984.2014.0069

[14] Kim, P.T., Lee, H.J., Kim, T.G. and Jeon, I.H. (2014) Current Approaches for Carpal Tunnel Syndrome. Clinics in Orthopedic Surgery, 6, 253-257.

https://doi.org/10.4055/cios.2014.6.3.253

[15] Dejaco, C., Stradner, M., Zauner, D., Seel, W., Simmet, N.E., Klammer, A., Quasthoff, S., et al. (2013) Ultrasound for Diagnosis of Carpal Tunnel Syndrome: Comparison of Different Methods to Determine Median Nerve Volume and Value of Power Doppler Sonography. Annals of the Rheumatic Diseases, 72, 1934-1939. https://doi.org/10.1136/annrheumdis-2012-202328

[16] Ghasemi-Esfe, A.R., Khalilzadeh, O., Vaziri-Bozorg, S.M., Jajroudi, M., Shakiba, M., Mazloumi, M. and Rahmani, M. (2011) Color and Power Doppler US for Diagnosing Carpal Tunnel Syndrome and Determining Its Severity: A Quantitative Image Processing Method. Radiology, 261, 499-506.

https://doi.org/10.1148/radiol.11110150 